\title{
X-ray Absorption (XRA): A New Technique for the Characterization of Granular Activated Carbons
}

\author{
Jeamichel Puente Torres ${ }^{1,2}$, Harold Crespo Sariol ${ }^{3}$, Thayset Mariño Peacok ${ }^{3}$, Jan Yperman ${ }^{4, *}$ (D), \\ Peter Adriaensens 4 (D), Robert Carleer ${ }^{4}$ (D) and Ángel Brito Sauvanell 5
}

1 Faculty of Electrical Engineering, Universidad de Oriente, Santiago de Cuba 90600, Cuba; jeamichelp@gmail.com

2 Provincial Center of Electro-Medicine, Department of Biomedical Metrology, Universidad de Oriente, Santiago de Cuba 90600, Cuba

3 Applied Acoustic Laboratory, Faculty of Chemical Engineering, Universidad de Oriente, Santiago de Cuba 90600, Cuba; harold@uo.edu.cu (H.C.S.); peacok@uo.edu.cu (T.M.P.)

4 Research Group of Applied and Analytical Chemistry, Faculty of Sciences, Hasselt University, 3590 Diepenbeek, Belgium; peter.adriaensens@uhasselt.be (P.A.); robert.carleer@uhasselt.be (R.C.)

5 Energetic Efficiency Center, Faculty of Chemical Engineering, Universidad de Oriente, Santiago de Cuba 90600, Cuba; albrito@uo.edu.cu

* Correspondence: jan.yperman@uhasselt.be; Tel.: +32-11-268295

Citation: Puente Torres, J.; Crespo Sariol, H.; Mariño Peacok, T.; Yperman, J.; Adriaensens, P.; Carleer, R.; Brito Sauvanell, Á. X-ray Absorption (XRA): A New Technique for the Characterization of Granular Activated Carbons. Materials 2021, 14, 91. https://doi.org/10.3390/ ma14010091

Received: 18 November 2020 Accepted: 11 December 2020 Published: 28 December 2020

Publisher's Note: MDPI stays neutral with regard to jurisdictional claims in published maps and institutional affiliations.

Copyright: () 2020 by the authors. Licensee MDPI, Basel, Switzerland. This article is an open access article distributed under the terms and conditions of the Creative Commons Attribution (CC BY) license (https: / creativecommons.org/ licenses/by/4.0/).

\begin{abstract}
The X-ray absorption (XRA) method using digital image processing techniques is a reliable technique to determine the exhaustion degree of granular activated carbons (GACs). Using an innovative digital image processing technique, the identification of individual adsorbed molecules or ions in a GAC was possible. Adsorption isotherm models (Langmuir and Freundlich) were used to simulate the adsorption equilibrium data of Methylene Blue (MB), nickel, cobalt and iodine. Freundlich equation was found to have the highest value of $R^{2}$ compared with Langmuir. The identification of distinctive patterns applying XRA for different adsorbed ions and molecules onto GAC was explored. It is demonstrated that unique XRA configurations for each adsorbed ion or molecule are found, as well as a proportional relationship between its incident energy (needed to achieve maximum photon attenuation) and the (effective) atomic number, the adsorbate mass and the molar or atomic mass of adsorbed molecule or ion. XRA method in combination with image histogram modifications was used to obtain a digital signature of adsorbed ions/molecules, giving distinct GSI values for each one in the used energy range. Probabilistic models prove that XRA results are within relationships between effective atomic number and photonic interaction probability, reinforcing the potentialities of XRA for monitoring (multi-)ion and/or molecule combinations on GAC using advanced digital image processing techniques. It was proved that the proposed approach could assess different adsorbed ions/molecules onto GACs in water purification systems.
\end{abstract}

Keywords: activated carbon; X-ray absorption; digital image processing; adsorption

\section{Introduction}

X-ray were discovered by the German physicist Wilhelm K. Röntgen (1845-1923) for which he won the Nobel Prize in 1901. While X-ray have been used for commercial elemental analysis since the 1950s, X-ray spectroscopy is much older than that, dating back to 1909 when Charles G. Barkla found a relationship between X-ray radiating from an element and its atomic weight. In 1913, Henry G.J. Moseley (1887-1915) found a linear relation between the square root of the frequency of $X$-rays corresponding with the $K$ line transitions in an X-ray spectrum (K-alpha lines) and the atomic number $(Z)$ of 40 elements. He was credited with the revision of the periodic table based on $Z$ rather than the atomic mass (A). He later laid the foundation for identifying elements in X-ray spectroscopy by establishing a relationship between frequency (energy) and the atomic number, a basis of X-ray spectrometry [1]. According to the Rutherford-Bohr model of the atom, electrons 
orbit around a positive nucleus. Only certain orbital states with specific energies exist, and these are defined by quantum numbers. When increasing $\mathrm{Z}$, orbits are occupied on the basis of minimum energy, those nearest the nucleus, and therefore the most tightly bound, being filled first. Orbital energy is determined mainly by the principal quantum number [2].

The populations of the inner shells are governed by the Pauli exclusion principle, which states that only one electron may possess a unique set of quantum numbers [3]. Valence electrons occupying outer orbits are usually not directly involved in the production of X-ray spectra, which are therefore largely unaffected by chemical bonding. The most intense $K$ line is $K \alpha_{1}$ (the less intense $K \alpha_{2}$ line is usually not resolved, and the combined line is designated $K \alpha$ ). The most intense $L$ line is $L \alpha_{1}$. Because of the splitting of the $L$ shell into three subshells, the $L$ spectrum is more complex than the $K$ spectrum and contains at least 12 lines, although many of these are weak [1-3]. Energies are measured in electron volt $(\mathrm{eV}), 1 \mathrm{eV}$ being the energy corresponding to a change of $1 \mathrm{~V}$ in the potential of an electron $\left(=1.602 \times 10^{-19} \mathrm{~J}\right)$. This unit is applicable to both X-ray and electrons. The critical excitation energy $\left(E_{C}\right)$ is the minimum energy needed for bombarding electrons (or other high-energy particles) in order to create an initial vacancy. In electron probe analysis, the incident electron energy $\left(E_{0}\right)$ must exceed $\mathrm{E}_{\mathrm{C}}$ and should preferably be at least twice $E_{\mathrm{C}}$ to give reasonably high excitation efficiency $[1,2]$. For atomic numbers above about 35 , it is common to change from $K$ to $L$ lines to avoid the need for an excessively high electron beam energy (which has undesirable implications with respect to the penetration of the electrons in the sample (penetration depth), and in any case may exceed the maximum available accelerating voltage).

However, for the application in this work, penetration power results in a useful tool to acquire the needed information, considering that all previous considerations are done using the photons that pass through the sample. The objective of qualitative analysis is to find which elements are present in an unknown specimen by identifying the lines in the X-ray spectrum using tables of energies or wavelengths. Ambiguities are rare and can invariably be resolved by considering additional lines as well as the main one.

On the other hand, new techniques based on X-ray absorption technology using medical images are getting visibility for the characterization of porous materials. Medical images utilize several different physical principles or image modalities for its formation. An X-ray image obtained from the exposition of matter to X-ray provides a contrast of intervening structures [4] as a direct function of its density $(\rho)$ and $Z$ (atomic number). The digitalized X-ray image is a grey-scale matrix that can be in different formats depending on the nature of the image. For binary or intensity images, image histogram constitutes a useful tool for analyzing the characteristics of the resultant image, providing important information about the intensity levels and the total pixels in the image [4].

Since X-ray methods have been successfully applied to determine the texture and elemental composition of different materials, the use of advanced digital images processing on digital X-ray radiography (XRA) is an interesting and suitable method to explore for detecting different adsorbed ions and/or molecules and distribution in granular activated carbons (GACs). In this study, two models (Langmuir and Freundlich) were used to describe the sorption process of nickel, cobalt, MB and iodine onto GAC. Furthermore, XRA method was used as an indirect method for determining distinctive patterns for each adsorbed molecule or ion. Interesting relationships between incident energy to achieve maximum photon attenuation, adsorbate mass, (effective) atomic number and atomic mass or molar mass of adsorbed ions or molecules were found, allowing to detect typical grey scale intensity (GSI) values for each adsorbed ion or molecule in the analyzed energy range as well as to formulate conclusions about its reliability using probabilistic models. The main purpose of this paper is to prove that the XRA technique can identify (qualitative analysis) and quantify (quantitative analysis) adsorbed ions and molecules on GAC. 


\section{Materials and Methods}

\subsection{Chemicals}

Nickel (Ni) is a transition metal, with atomic number 28 and main oxidation state + II situated in Group 10 of the Periodic Table (at. wt. 58.71). Cobalt (Co) is a ferromagnetic metal, with atomic number 27 and main oxidation states of + II and + III (at. wt. 58.93). Molecular iodine $\left(I_{2}\right)$ (mol. wt. 253.8) (analytical grade, Merck) was dissolved in water using Kl (analytical grade, Merck KGaA, Darmstadt, Germany) with in situ formation of the triiodide anion $\left(\mathrm{I}_{3}{ }^{-}\right.$) (mol. wt. 380.7). Methylene Blue (MB) (analytical grade, Merck KGaA, Darmstadt, Germany) in aqueous solution is present as a positive charged organic ion with molecular formula $\mathrm{C}_{16} \mathrm{H}_{18} \mathrm{~N}_{3} \mathrm{ClS}$ (mol. wt. 319.85). The chemical structure of $\mathrm{MB}^{+}$ ion is shown in Figure 1.<smiles>CN(C)c1ccc2nc3ccc(=[N+](C)C)cc-3sc2c1</smiles>

Figure 1. Chemical structure of Methylene Blue ion.

\subsection{Adsorbent}

A commercial granular activated carbon, from Norit (Cabot Norit GmbH, Rheinfelden, Germany), was used as adsorbent. This GAC was studied in the past and its specifications can be found in [5,6]. GAC samples for adsorption were dried at $200{ }^{\circ} \mathrm{C}$ during $1 \mathrm{~h}$ in a Boxun oven (BGZ Series) applying the ASTM Standard Test Methods D2267-04 for moisture determination. Samples were held overnight in a silica-gel desiccator until being measured.

\subsection{Preparation of Metal and Dye Solutions}

A stock solution of $5 \mathrm{~g} / \mathrm{L}$ of nickel and cobalt was prepared by dissolving $\mathrm{NiSO}_{4} \cdot 6 \mathrm{H}_{2} \mathrm{O}$ (analytical grade, Merck KGaA (Darmstadt, Germany)) and $\mathrm{CoSO}_{4} \cdot 7 \mathrm{H}_{2} \mathrm{O}$ (analytical grade, Merck) in Milli-Q water. Different concentrations were obtained by diluting the stock solution $(25,50,125,200,450$ and $700 \mathrm{mg} / \mathrm{L})$. Solution $\mathrm{pH}(\mathrm{pH}=5)$ was fixed using $\mathrm{H}_{2} \mathrm{SO}_{4}$ (0.5\%) (analytical grade, Merck KGaA (Darmstadt, Germany)); $0.3 \mathrm{~g}$ (for nickel isotherm) and $0.15 \mathrm{~g}$ (for cobalt isotherm) of GAC was added to each flask with $30 \mathrm{~mL}$ of solution and shaken for $24 \mathrm{~h}$ at room temperature. The concentration of metal ions (Ni and Co) was determined using an inductively coupled plasma spectrophotometer (PerkinElmer Optima 3000 DV ICP-AES (PerkinElmer Inc., Shelton, CT, USA)) with an axial plasma configuration.

A stock solution of $1 \mathrm{~N}$ iodine was prepared according to the Standard Test Method for determination of iodine number of GAC. All other solutions were prepared by diluting this stock solution $(0.05,0.1,0.2,0.4,0.6$ and $0.8 \mathrm{~N}) ; 0.15 \mathrm{~g}$ of GAC was added to each flask of $30 \mathrm{~mL}$ solution and shaken for $24 \mathrm{~h}$ at $25^{\circ} \mathrm{C}$. Concentrations were measured by titration using a standardized solution of $\mathrm{Na}_{2} \mathrm{~S}_{2} \mathrm{O}_{3}(0.1 \mathrm{~N})$ (analytical grade, Merck).

A stock solution of Methylene Blue (analytical grade, Merck) at a concentration of $5 \mathrm{~g} / \mathrm{L}$ was prepared; $30 \mathrm{~mL}$ of the diluted stock solution $(250,500,750,1000,1500$ and $2000 \mathrm{mg} / \mathrm{L}$ ) was added to different flasks with $0.15 \mathrm{~g}$ of GAC and shaken for $24 \mathrm{~h}$ at $25^{\circ} \mathrm{C}$. Solution $\mathrm{pH}(\mathrm{pH}=10)$ was fixed using $0.1 \mathrm{~mol} / \mathrm{L}$ of $\mathrm{NaOH}$ (analytical grade, Merck). Solution concentrations were determined using a spectrophotometer (Ultrospec, Biochrom Fisher Scientific UK Ltd., Loughborough, UK), at $\lambda=664 \mathrm{~nm}$ and a calibration range of $0.5-5 \mu \mathrm{g} / \mathrm{L}$.

\subsection{Langmuir Isotherm}

Langmuir equation [7] was developed considering the following assumptions: (1) a fixed number of accessible sites is available on the adsorbent surface and all active 
sites have the same energy; (2) adsorption is reversible; (3) once an adsorbate occupies a site, no further adsorption can occur on that site; and (4) there is no interaction between adsorbate species. Langmuir isotherm model is used to predict the sorption of dissolved molecules/elements onto a solid phase [7,8]. Langmuir model is described in Equation (1) [9]:

$$
q_{e}=\frac{q_{m} \cdot K_{L} \cdot C_{e}}{1+K_{L} \cdot C_{e}}
$$

where $q_{e}$ is the amount of adsorbate uptake at equilibrium (in $\mathrm{mg} / \mathrm{g}$ ), $q_{m}$ is the maximum capacity of adsorption of an adsorbate (in $\mathrm{mg} / \mathrm{g}$ ), $C_{e}$ is the adsorbate concentration at equilibrium (in $\mathrm{mg} / \mathrm{L}$ ) and $K_{L}$ is the Langmuir constant related to the affinity between adsorbent and adsorbate (in L/mg).

Limitations in using the Langmuir model by its linear equation have been highlighted recently [9]. The transformation of data for linearization can result in modifications of error structure, introducing an error into the independent variable and altering the weight of each data point, which often leads to differences in the fitted parameter values of the Langmuir model between its linear and nonlinear versions.

Separation factor or equilibrium parameter $\left(R_{L}\right)$ represents an essential tool in order to describe the essential characteristics of the Langmuir isotherm, if Langmuir model adequately describes the experimental data. This parameter is a constant separation factor (dimensionless) of the solid-liquid adsorption system, which is defined as follows [9]:

$$
R_{L}=\frac{1}{1+K_{L} \cdot C_{0}}
$$

where $R_{L}$ is Langmuir equilibrium parameter (dimensionless) and $C_{0}$ is the initial adsorbate concentration $(\mathrm{mg} / \mathrm{L})$.

\subsection{Freundlich Isotherm}

Freundlich isotherm model assumes that the adsorption process takes place on a heterogeneous surface [10]. Freundlich model is one of the earliest empirical equations used to describe equilibrium data. Freundlich nonlinear equation is described in Equation (3) [10].

$$
q_{e}=K_{F} \cdot C_{e}^{n}
$$

where $K_{F}$ is the Freundlich constant (in $\frac{\frac{m g}{g}}{\left(\frac{m g}{L}\right)^{n}}$ ) and $n$ is the Freundlich intensity parameter (dimensionless).

The parameter $n$ in Freundlich model indicates the magnitude of the adsorption driving force or the surface heterogeneity $[9,10]$.

\subsection{Effective Atomic Number}

When dealing with a molecule or a mixture of molecules, it is convenient to describe this system by an effective atomic number $\left(Z_{\text {eff }}\right)$. In the energy range where Compton absorption is important, the absorption is independent of $Z$ and calculation of $Z_{\text {eff }}$ is unnecessary. The energy region of interest when discussing $Z_{\text {eff }}$ is then from 20 to $100 \mathrm{keV} \mathrm{[11],}$ where the photoelectric process is dominant over the Compton process [11,12] and radiologic machines are equipped to work. Calculation of $Z_{e f f}$ of the MB ion for total photon interaction was carried out using Equation (4) [11].

$$
Z_{e f f}=\sqrt[m]{a_{1} Z_{1}^{m}+a_{2} Z_{2}^{m}+\ldots+a_{z} Z_{z}^{m}}
$$

Coefficients $a_{i}$ can be defined using the following equation:

$$
a_{i}=\frac{\frac{N_{A} \cdot Z_{i} \cdot w_{i}}{A_{i}}}{\sum_{i} \frac{N_{A} \cdot Z_{i} \cdot w_{i}}{A_{i}}} \text { for } i=1, \mathrm{z}
$$


where $N_{A}$ is the Avogadro number, $Z_{i}$ is the atomic number of element $i, A_{i}$ is the atomic weight of element $i, w_{i}$ is the weight proportion of element $i$ (dimensionless) and $m$ is the effective dependency of photoelectric effect in the energy range used (20-100 keV).

Mayneord [9] first introduced $Z_{\text {eff }}$ and recommended an exponent $m=2.94$. The determination of $Z_{\text {eff }}$ involves considerable effort; theoretical calculations should be verified considering experimental data. Weight proportions for each constituent element of MB ion (see Section 2.1) were calculated online using XCOM software version 1.0 (NIST Technologies, Gaithersburg, MD, USA) $[13,14]$. When an MB molecule is dissolved in aqueous solution, a complete dissociation takes place into $\mathrm{MB}^{+}$and/or $\mathrm{MB}^{2+}$ depending on the $\mathrm{pH}$. At $\mathrm{pH}=10, \mathrm{MB}$ ion will be present only as $\mathrm{MB}^{+}$. Table 1 depicts weight proportions values, atomic number and atomic weight for each element of the MB ion for calculating its $Z_{\text {eff. }}$.

Table 1. Weight proportion values, atomic number and atomic weight for each constituent element of MB ion calculated using XCOM software.

\begin{tabular}{cccc}
\hline Element & $W$ & $Z$ & $A$ \\
\hline $\mathrm{H}$ & 0.056722 & 1 & 1 \\
$\mathrm{C}$ & 0.600817 & 6 & 12 \\
$\mathrm{~N}$ & 0.131372 & 7 & 14 \\
$\mathrm{~S}$ & 0.100251 & 16 & 32 \\
\hline
\end{tabular}

$Z_{\text {eff }}$ of the MB ion in the energy range used (20-100 keV) was calculated using the values showed in Table 1 and Equation (5) being approximately 9. For the iodine molecule, $Z_{\text {eff }}=Z$.

\subsection{X-ray Digital Radiography Experiments (XRA)}

$X$-ray radiography experiments were performed at seven different energies for each analyzed ion and molecule. Six $q_{e}$ values (see Table 2 ) were analyzed using $X$-ray radiography. GAC charged with $\mathrm{Ni}$, $\mathrm{Co}$ and $\mathrm{MB}$ were analyzed using 22, 27, 33, 40, 50, 60 and $70 \mathrm{keV}$, respectively. Energies above $50 \mathrm{keV}$ caused an increase in the penetrating power of the incident photon beam; as more photons pass through the material, darker images are obtained with fewer differences in GSI values, making the experiment useless for Ni, Co and MB. GAC charged with iodine were analyzed using 40, 50, 60, 70, 80, 90 and $100 \mathrm{keV}$, respectively. Whether images were obtained for GAC charged with iodine using energy values below $40 \mathrm{keV}$, as only a minor amount of photons passes through the material, no significant differences in GSI values were detected for the analyzed samples. When energies above $150 \mathrm{keV}$ were used to analyze GAC iodine samples, darker images were obtained and it was not possible to detect significant differences in GSI values between samples. Table 2 depicts $q_{e}$ and $C_{e}$ values for GAC charged with, respectively, Ni, Co, MB and $I_{2}$ to develop X-ray experiment.

Table 2. $q_{e}$ and $C_{e}$ values for GAC samples charged with $\mathrm{Ni}, \mathrm{Co}, \mathrm{MB}$ and $\mathrm{I}_{2}$.

\begin{tabular}{cccccccc}
\hline \multicolumn{2}{c}{ Nickel } & \multicolumn{2}{c}{ Cobalt } & \multicolumn{2}{c}{ Methylene Blue } & \multicolumn{2}{c}{ Iodine } \\
\hline$C_{e}$ & $q_{e}$ & $C_{e}$ & $q_{e}$ & $C_{e}$ & $q_{e}$ & $C_{e}$ & $q_{e}$ \\
\hline 0 & 0 & 0 & 0 & 0 & 0 & 0 & 0 \\
10.4 & 1.46 & 14.9 & 2.01 & 0.0395 & 49.97 & 665 & 451 \\
20.8 & 2.92 & 29.8 & 4.03 & 0.079 & 99.94 & 1330 & 903 \\
74.05 & 5.09 & 86.85 & 7.62 & 23.22 & 145.31 & 9077 & 1232 \\
127.3 & 7.27 & 143.9 & 11.21 & 46.36 & 190.68 & 16,825 & 1561 \\
335 & 11.51 & 312.15 & 27.58 & 374.93 & 224.99 & 39,036 & 2099 \\
542.7 & 15.73 & 480.4 & 43.95 & 703.5 & 259.3 & 61,248 & 2638 \\
\hline
\end{tabular}

$q_{e}=\frac{C_{0}-C_{e}}{m_{\text {adsorbent }}} V_{\text {sol }}\left(V_{\text {sol }}=30 \mathrm{~mL} ; m_{\text {adsorbent }}=0.15 \mathrm{~g}\right.$ for $\mathrm{Co}, \mathrm{MB}$ and $I_{2}$ and $0.30 \mathrm{~g}$ for $\mathrm{Ni} ; \mathrm{T}=25^{\circ} \mathrm{C}$; $e_{\text {quilibrium }}=24 \mathrm{~h}, \mathrm{C}_{0}$ see Section 2.3). 
Experiments applying energies between 22 and $33 \mathrm{keV}$ (related to penetration depth) were conducted at $125 \mathrm{mAs}$ (related to the amount of X-ray reaching the sample) [15] using a TOSHIBA Mamorez-mgu 100d, TOSHIBA, Tokyo, Japan. X-ray equipment used for mammography studies in manual mode (the energy of incident $X$-ray photons needed to be adjusted manually). X-ray experiments applying energies between 40 and $100 \mathrm{keV}$ were conducted using $40 \mathrm{mAs}$ [15] in a TOSHIBA KXO-36 s (used for general clinical radiography). X-ray radiography experiments were performed according to the methodology described in [15]. XRA experiments and data processing of the X-ray digital images were performed following the images processing algorithm applied in $[15,16]$. The spatial concentration $\left(S_{C}\right)$ (in pixel), for a specific grey-scale intensity level (GSI) was related with the normalized grey scale value when the total number of pixels maximizes, i.e., $T_{P}(G S I)[15,16]$. The mathematical analysis of the digital X-ray radiographic images was performed using dedicated software developed in MATLAB ${ }^{\circledR} 2015$ specifically for this application. A focal distance of $60 \mathrm{~cm}$ and a sample thickness of $1.2 \mathrm{~cm}$ were used for all the experiments.

\subsection{Relationship between Grey-Scale Intensity (GSI) and Mass Attenuation Coefficient Using $X R A$. Spatial Concentration $\left(S_{C}\right)$}

Since photoelectric effect predominates for the voltage range used for clinical Xray radiography (20-120 keV), photon attenuation can be expressed using the formula presented in Equation (6) [11].

$$
N=N_{0} \cdot e^{-\mu . x}
$$

where $N$ is the intensity or number of attenuated photons (dimensionless), $N_{0}$ is the initial Intensity or number of incident photons (dimensionless), $\mu$ is the linear absorption coefficient (in $\mathrm{cm}^{-1}$ ) and $\chi$ is the sample thickness (in $\mathrm{cm}$ ).

According to recent publications $[15,16]$, it is possible to establish a mathematical relationship between attenuated photons $(N)$ and GSI using the Equation (7) [15].

$$
G S I=f(N)
$$

According to Equation (8), it is possible to express GSI as an equivalent exponential function of the initial grey-scale intensity (GSI $)$ using Equation (8) [15].

$$
G S I=G S I_{0} \cdot e^{\mu \cdot x}
$$

The mass attenuation coefficient $(\mathrm{t})$ is obtained from the linear absorption coefficient $(\mu)$ divided by the density of the material $(\rho)$. This coefficient is independent of the material density [9]. The grey-scale intensity of incident photons $\left(G S I_{0}\right)$ was calculated according to the method in [15]. The density of the virgin adsorbent used $(G A C)$ is approximately $0.38 \mathrm{~g} / \mathrm{cm}^{3}$. Relative density values of each ion or molecule $\left(\mathrm{Ni}, \mathrm{Co}, \mathrm{MB}\right.$ and $\left.I_{2}\right)\left(\rho_{i}\right)$ were calculated using $q_{i}$ and the density of the virgin adsorbent GAC as shown in Equation (9).

$$
\rho_{i}=0.38 \cdot q_{i}
$$

where $\rho_{i}$ is the relative density of adsorbed ion or molecule $i\left(\mathrm{in} \mathrm{g} / \mathrm{cm}^{3}\right)$ and $q_{i}$ is the ratio between amount of adsorbate uptake at equilibrium and maximum capacity of adsorption of an adsorbent (dimensionless).

Equation (8) can be reorganized as:

$$
\mu=\frac{\ln \left(\frac{G S I}{G S I_{0}}\right)}{x}
$$

Using Equation (10), it is possible to express the mass attenuation coefficient as a function of the grey-scale intensity (Equation (11)). 


$$
\mathrm{t}_{i}=\frac{\mu}{\rho_{i}}=\frac{\ln \left(\frac{G S I}{G S I_{0}}\right)}{\rho_{i} \cdot x}
$$

where $t_{i}$ is the mass attenuation coefficient of ion or molecule $i$ (in $\mathrm{cm}^{2} / \mathrm{g}$ ).

An increase in the X-ray energy causes a decreasing trend in GSI values [15,16]; at the same time, considering Equation (10), when GSI values tend to decrease, the mass attenuation coefficient should decrease in a proportional way.

XRA method uses digital image processing on digital X-ray radiography. An X-ray beam of variable energy between 20 and $120 \mathrm{keV}$, a sample thickness of $12 \mathrm{~mm}$ and a focal distance of $60 \mathrm{~cm}$ were used for all the experiments. The XRA experiments and data processing of the X-ray digital images were performed following the image processing algorithm applied in [15]. The spatial concentration $S_{C}$ (in pixel) for a specific GSI level was related with the normalized grey scale value when the total number of pixels is maximized, i.e., $T_{P}(G S I)$, and can be expressed by Equation $(12)[15,16]$.

$$
S_{C}(G S I)=T_{P}(G S I)
$$

where $S_{C}(G S I)$ is the spatial concentration of the intensity level GSI (in pixel).

The mathematical analysis of the digital X-ray radiographic images was performed using dedicated software developed in MATLAB ${ }^{\circledR} 2015$ (MathWorks, Natick, MA, USA) specifically for this application.

2.9. Relationship between Energy (to Achieve Maximum Photon Attenuation), Adsorbate Mass, Molar Mass and Atomic Number

The relative concentration of an ion or molecule $i$ adsorbed by GAC can be mathematically expressed using Equation (13).

$$
C_{i}=\frac{m_{i}}{m_{T}}
$$

where $C_{i}$ is the relative concentration of ion or molecule $i(\mathrm{mg} / \mathrm{g}), m_{i}$ is the mass of ion or molecule $i$ adsorbed (in $\mathrm{mg}$ ) and $m_{T}$ is the total mass of sample studied (mass of ion or molecule adsorbed and mass of adsorbent) (g).

Global density $\rho_{T}$ can be calculated using Equation (14):

$$
\rho_{T}=\frac{m_{T}}{V_{T}}
$$

where $V_{T}$ is the total solid sample volume in the cuvette (in $\mathrm{cm}^{3}$ ).

According to Equations (13) and (14), it is possible to express the relative concentration of ion or molecule $i$ using Equation (15).

$$
C_{i}=\frac{m_{i}}{\rho_{T} \cdot V_{T}}
$$

Considering the shape of the X-ray cuvette, the total volume $V_{T}$ can be mathematically expressed using Equation (16).

$$
V_{T}=a \cdot b \cdot x
$$

where $a$ is X-ray cuvette depth (in $\mathrm{cm}$ ), $b$ is X-ray cuvette width (in $\mathrm{cm}$ ) and $x$ is X-ray cuvette height or sample thickness (in $\mathrm{cm}$ ).

Substituting Equation (16) into Equation (15) and assuming $a=b=1$, considering that changes in $a$ and $b$ cause proportional changes in $m_{i}$ and $C_{i}$, it is possible to obtain Equation (17):

$$
C_{i}=\frac{m_{i}}{\rho_{T} \cdot x}
$$


Molar mass or atomic mass $\left(M_{i}\right)$ can be used as a conversion factor between mass $m_{i}$ (in $\mathrm{mg}$ ) and amount of substance $o_{i}$ (in mmol) of ion or molecule $i$ :

$$
m_{i}=o_{i} \cdot M_{i}
$$

Substitution of Equation (18) into Equation (17) gives:

$$
C_{i}=\frac{o_{i} \cdot M_{i}}{\rho_{T} \cdot x}
$$

The behavior of the photoelectric effective section with the energy changes for energies below or above $0.5 \mathrm{MeV}$. For energies above $0.5 \mathrm{MeV}$, electron behavior is relativistic and photoelectric effective section decreases inversely proportional to the energy (hv) [10]. A global description of the photoelectric effective section or interaction probability for a specific ion or molecule for energies below $0.1 \mathrm{MeV}$ (between 20 and $100 \mathrm{keV}$ ) is given by Equation (20) [11-14].

$$
P_{i} \sim \frac{Z_{i}^{k}}{E^{l}}
$$

for $4<k<5$ and $1<l<3.5$ [11], where $P_{i}$ is the photoelectric interaction probability of element $i$ (dimensionless), $Z_{i}$ is the (effective) atomic number of ion or molecule $i$ (dimensionless), $E$ is the energy of the incident photon beam (in $\mathrm{keV}$ ), $k$ is the effective dependency of photoelectric effective section with (effective) atomic number $Z$ (dimensionless) and $I$ is the effective dependency of photoelectric effective section with energy $E$ (dimensionless).

For low (effective) atomic number elements/molecules, it is recommended to use $k=4$ and $l=3$ [12-14]. Cunningham [11] suggested using $k=4.8$ and $l=3.5$ for elements/molecules with (effective) atomic number equal to or below 50. Considering that an increase in the relative concentration of the analyzed ion/molecule $(i)$ causes an increase for atoms/molecules with atomic or effective atomic number $Z_{i}$, Equation (20) can be rewritten as:

$$
P_{i} \sim o_{i} \frac{Z_{i}^{k}}{E^{l}}
$$

Using Equation (19) in Equation (21), one obtains:

$$
P_{i} \sim \frac{C_{i} \cdot x \cdot \rho_{T}}{M_{i}} \cdot \frac{Z_{i}^{k}}{E^{l}}
$$

Assuming the maximum interaction probability $(P=1)$ for a specific ion or molecule $i$, we obtain:

$$
1 \sim \frac{C_{i} \cdot x \cdot \rho_{T}}{M_{i}} \cdot \frac{Z_{i}{ }^{k}}{E^{l}}
$$

Which allows defining $E$ as:

$$
E \sim \sqrt[l]{C_{i} \cdot x \cdot \frac{Z_{i}{ }^{k} \cdot \rho_{T}}{M_{i}}}
$$

From substitution of Equation (17) into Equation (24), we obtain:

$$
E \sim \sqrt[l]{m_{i} \cdot \frac{Z_{i}^{k}}{M_{i}}}
$$

Adsorption amount of an ion or molecule $i\left(m_{i}\right)$ adsorbed per gram of adsorbent $\left(m_{a d s b}\right)$ as defined by Langmuir or Freundlich isotherm can be described using Equation $(26)[9,10]$.

$$
q_{e}=\frac{m_{i}}{m_{a d s b}}
$$


Multiplying $q_{e}$ parameter by the density of the used adsorbent, it is possible to obtain the adsorbate concentration $\left(C_{i}\right)$ expressed as mass-volume relation in the solid phase using Equation (27):

$$
q_{e} \cdot \rho_{a d s b}=\frac{m_{i}}{m_{a d s b}} \cdot \rho_{a d s b}=\frac{m_{i}}{V_{T}}
$$

Rearranging Equation (27) allows the calculation of the adsorbate mass using Equation (28).

$$
m_{i}=q_{e} \cdot \rho_{a d s b} \cdot V_{T}
$$

The adsorbent density value $\left(\rho_{a s d}\right)$ is constant $\left(0.38 \mathrm{~g} / \mathrm{cm}^{3}\right.$, Section 2.9$)$; the volume of analyzed samples is also constant, and it has an approximate value of $1.2 \mathrm{~cm}^{3}$ [15]. Equation (25) describes a proportional relationship between energy (keV) and atomic or effective atomic number, molar mass and the mass of ion or molecule $i$. This means that the energy value needed to achieve maximum photon attenuation (pixels in " 1 " in XRA images) is proportional with the amount of adsorbate that can be adsorbed by a determinate mass of GAC or other absorbent material in a fixed volume. Taking into account the above and using the experimental data, it could be possible to calculate a physical constant able to directly describe the relation between energy, atomic or effective atomic number, molar mass and adsorbate mass.

\subsection{Probabilistic Approach for Comparison between Elements/Molecules}

Considering that Equation (25) describes a proportional relationship and not an equality, it was necessary to verify the reliability of this mathematical expression. Values of exponent $k$ and $l$ can change in function of the energy range used; however, those values should present limited variations between 20 and $120 \mathrm{keV}$ (energy range used for the experiment) with a small error range compared to the values reported in the literature [11-14]. Using Equation (25), it is possible to develop a probabilistic comparison between optimal energy values $\left(E_{1}\right.$ and $\left.E_{2}\right)$ found for analyzed ions or molecules using Equation (29).

$$
\frac{E_{1}}{E_{2}} \approx \frac{\sqrt[l]{m_{1} \cdot \frac{z_{1} k_{1}}{M_{1}}}}{\sqrt[l]{m_{2} \cdot \frac{z_{2} k_{2}}{M_{2}}}}
$$

where $E_{1}$ and $E_{2}$ are energy values found for the best correlation fit between $S_{C}$ and $q_{e}$ for ions or molecule 1 and 2 (in keV).

Using calculated values of adsorbate mass as well as energy values found for the best correlation fit between $S_{C}$ and $q_{e}$ for ions or molecule 1 and 2, atomic or effective atomic number, molar mass or atomic mass of analyzed molecule or ion, it is possible to obtain a $3 \mathrm{D}$ representation of the relation between ions or molecules, keeping exponent $l$ constant and analyzing the behavior of the exponent $k$ within the range proposed in the literature (in our case, between 4 and 5). If found energy values are correct, the exponent parameter $k$ should have an approximate numerical value for the values proposed in the literature [11] for each analyzed ion or molecule and in accordance with the atomic or effective atomic number. The relation between the ratio of energy values $\left(E_{1} / E_{2}\right)$ found for each ion or molecule 1 and 2 should be the same within a small error range.

\section{Results and Discussion}

\subsection{Isotherms for the Sorption Process}

Relationship between $C_{e}$ and $q_{e}$ can be used to evaluate the effectiveness of different models to describe experimental data [9]. 


\subsubsection{Langmuir Isotherms}

The nonlinear fitting of the experimental data by the Langmuir isotherm gives not that convincing results in view of their $R^{2}$ values, except for Ni. The values of $K_{L}, q_{m}$ and $R^{2}$ from the correlation between $q_{e}$ and $C_{e}$ are presented in Table 3.

Table 3. Nonlinear fitting parameters between $q_{e}$ and $C_{e}$ found using Langmuir adsorption model.

\begin{tabular}{cccccc}
\hline Element/Molecule & $\boldsymbol{q}_{\boldsymbol{m}}$ & $\boldsymbol{e}\left(\boldsymbol{q}_{\boldsymbol{m}}\right)$ & $\boldsymbol{K}_{\boldsymbol{L}}$ & $\boldsymbol{e}\left(\boldsymbol{K}_{\boldsymbol{L}}\right)$ & $\boldsymbol{R}^{\mathbf{2}}$ \\
\hline Nickel & 22 & 3 & 0.0040 & \pm 0.0010 & 0.98 \\
Cobalt & 23 & 4 & 0.0015 & \pm 0.0001 & 0.92 \\
Methylene Blue & 250 & 40 & 0.063 & \pm 0.055 & 0.86 \\
Iodine & 2680 & 400 & 0.00001 & \pm 0.00001 & 0.89 \\
\hline
\end{tabular}

(with $e(i)$ the error on parameter $i$ ).

Table 4 depicts the linear fitting results for the Langmuir relationship $C_{e} / q_{e}$ vs. $C_{e}$ for each adsorbed ion or molecule.

Table 4. Parameter results of $q_{m}$ and $K_{L}$ from the linear fitting between $C_{e} / q_{e}$ and $C_{e}$ using modified Langmuir adsorption equation: $\frac{C_{e}}{q_{e}}=\frac{1}{q_{m} \cdot K_{L}}+\left(\frac{1}{q_{m}}\right) \cdot C_{e}$.

\begin{tabular}{cccccc}
\hline Element/Molecule & $\boldsymbol{q}_{\boldsymbol{m}}$ & $\boldsymbol{e}\left(\boldsymbol{q}_{\boldsymbol{m}}\right)$ & $\boldsymbol{K}_{\boldsymbol{L}}$ & $\boldsymbol{e}\left(\boldsymbol{K}_{\boldsymbol{L}}\right)$ & $\boldsymbol{R}^{\mathbf{2}}$ \\
\hline Nickel & 13 & \pm 3 & 5 & \pm 1 & 0.71 \\
Cobalt & 30 & \pm 4 & 3 & \pm 1 & 0.28 \\
Methylene Blue & 251 & \pm 9 & 5 & \pm 1 & 0.99 \\
Iodine & 2366 & \pm 3 & 12 & \pm 4 & 0.92 \\
\hline
\end{tabular}

(with $e(i)$ the error on parameter $i$ ).

Now, only for $\mathrm{MB}$ and not for $\mathrm{Ni}$, a good fitting result is found between $C_{e} / q_{e}$ and $C_{e}$, as shown in Figure 2.

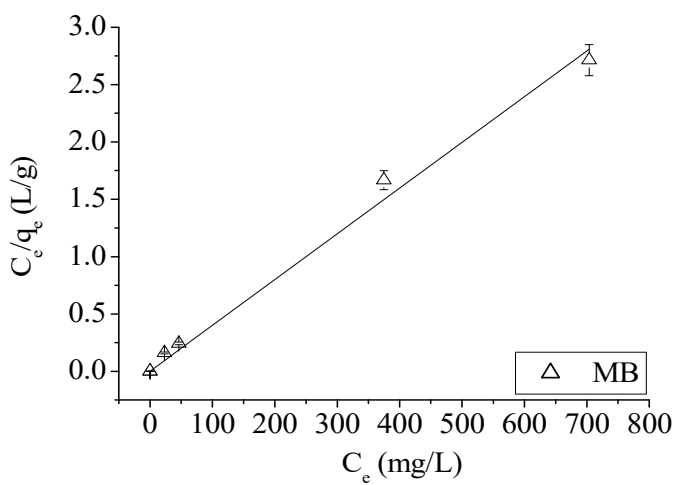

Figure 2. $C_{e} / q_{e}$ vs. $C_{e}$ relation for MB.

For the other ions and molecule, as demonstrated by Table 4, no good Langmuir linear fitting value for $R^{2}$ is obtained. Additionally, $K_{L}$ values are totally different from each other using both approaches (Tables 3 and 4). On the contrary, $q_{m}$ values are comparable but $R^{2}$ values are totally different. Error propagation on both parameters $K_{L}$ and $q_{m}$ behave complete differently according to which fitting approach is applied. This indicates that the obtained linear and nonlinear Langmuir fittings are not acceptable and are not suitable to describe the adsorption for these ions and molecule, certainly also in view of the very good Freundlich fitting results obtained. Nevertheless, Table 5 depicts the separation factor calculated for each adsorbed ion or molecule [9]. 
Table 5. Langmuir separation factors.

\begin{tabular}{ccc}
\hline Element/Molecule & $\boldsymbol{C}_{\boldsymbol{o}}(\mathrm{mg} / \mathrm{L})$ & $\boldsymbol{R}_{\boldsymbol{L}}$ \\
\hline Nickel & $25-700$ & $0.91-0.26$ \\
Cobalt & $25-700$ & $0.96-0.49$ \\
Methylene Blue & $250-2000$ & $0.059-0.008$ \\
Iodine & $3585-74,438$ & $0.96-0.57$ \\
\hline
\end{tabular}

A separation factor between 0 and 1 indicates favorable adsorption [9]. According to Table 5, separation factors between 0 and 1 are found for nickel, cobalt, MB and iodine, indicating a favorable adsorption of all those ions or molecule onto GAC.

\subsubsection{Freundlich Isotherms}

Equilibrium adsorption data of nickel, cobalt, MB and iodine onto GAC was tested with Freundlich isotherm model. Nonlinear fitting graphs for Freundlich isotherm model at room temperature $\left(25^{\circ} \mathrm{C}\right)$ are shown in Figure 3.

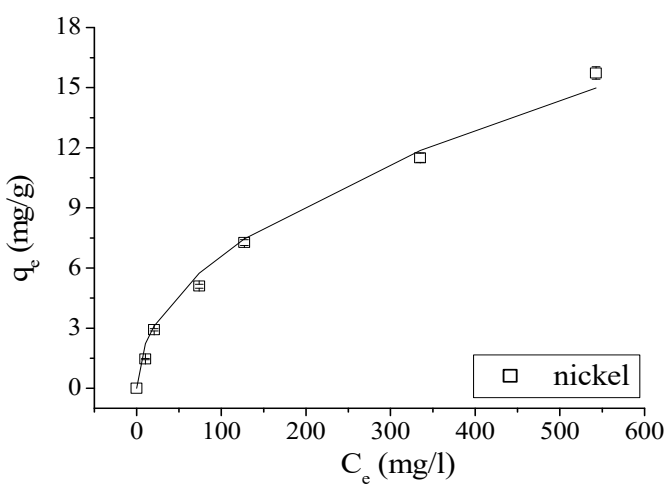

(a)

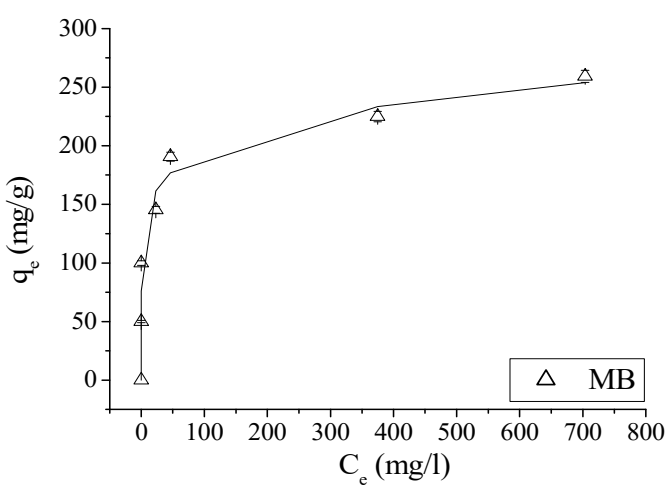

(c)

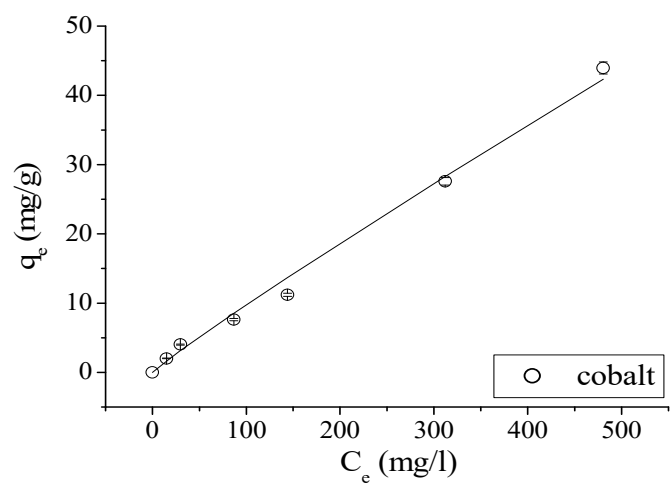

(b)

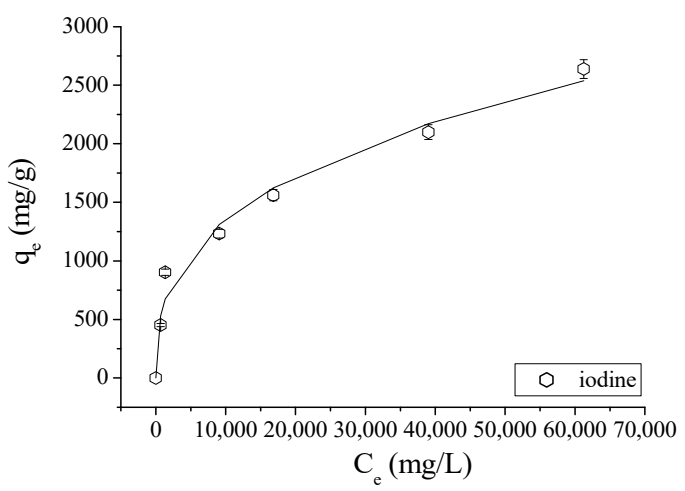

(d)

Figure 3. Adsorption isotherms for Freundlich model of: nickel (a); cobalt (b); $\mathrm{MB}$ (c); and iodine (d) onto GAC at $25^{\circ} \mathrm{C}$.

The values of $n$ and $R^{2}$ for the nonlinear fitting between $q_{e}$ and $C_{e}$ for Freundlich adsorption isotherms are presented in Table $6 \mathrm{a}$.

When applying linear fitting of the Freundlich model on obtained experimental data, the results presented in Table $6 \mathrm{~b}$ are obtained.

As could be expected (different propagation behavior of experimental errors using experimental data), slightly different values for the two parameters are found. According to the $R^{2}$ values shown in Table $6 \mathrm{a}, \mathrm{b}$, the Freundlich adsorption model describes the adsorption of analyzed ions and molecule onto GAC perfectly. The value of the parameter $n=1$ for cobalt, in the case of a nonlinear fitting, indicates that the adsorption process is linear $[9,10]$, as demonstrated in Figure $3 b$. On the other hand, linear fitting presents a value 
of $n<1$ for all ions and molecule, indicating that the adsorption process is favorable. $K_{F}$ and $n$ values are now comparable in value when using both fitting approaches. However, nonlinear fitting results have to be preferred as experimental error structure is differently modified in both approaches making linear fitting results questionable [9]. Based on $K_{F}$ values, the adsorption of $\mathrm{MB}$ is much faster than the one for $I_{2}$ (a factor two faster). Compared to the others, adsorptions for $\mathrm{Ni}$ and $\mathrm{Co}$ ions are very slow. This agrees with the steep exponential shape of $\mathrm{MB}$ and $I_{2}$ isotherms compared to the one of $\mathrm{Ni}$ and certainly with the linear shape of Co isotherm.

Table 6. Parameter results from nonlinear fitting between $q_{e}$ and $C_{e}$ using Freundlich model (a); and parameter results from linear fitting between $\log \left(q_{e}\right)$ and $\log \left(C_{e}\right)$ using Freundlich model $(\mathbf{b})$.

\begin{tabular}{|c|c|c|c|c|c|}
\hline Element/Molecule & $K_{F}$ & $e\left(K_{F}\right)$ & $N$ & $e(n)$ & $R^{2}$ \\
\hline \multicolumn{6}{|c|}{ (a) } \\
\hline Nickel & 0.72 & \pm 0.14 & 0.51 & \pm 0.01 & 0.99 \\
\hline Cobalt & 0.13 & \pm 0.04 & 1.00 & \pm 0.07 & 0.99 \\
\hline Methylene Blue & 106 & \pm 10 & 0.13 & \pm 0.01 & 0.99 \\
\hline Iodine & 53 & \pm 16 & 0.35 & \pm 0.02 & 0.99 \\
\hline \multicolumn{6}{|c|}{ (b) } \\
\hline Nickel & 0.44 & \pm 0.06 & 0.57 & \pm 0.01 & 0.99 \\
\hline Cobalt & 0.19 & \pm 0.05 & 0.86 & \pm 0.05 & 0.99 \\
\hline Methylene Blue & 89 & \pm 3 & 0.165 & \pm 0.008 & 0.99 \\
\hline Iodine & 40 & \pm 3 & 0.377 & \pm 0.008 & 0.99 \\
\hline
\end{tabular}

$q_{e}=K_{F} \cdot C_{e}^{n}$ (with $e(i)$ the error on parameter $\left.i\right) ; \log q_{e}=\mathrm{n} \cdot \log C_{e}+\log K_{F}($ with $e(i)$ the error on parameter $i)$.

\subsection{X-ray Absorption (XRA)}

$X$-ray digital radiographic data at each analyzed energy of incident photon beam were stored and independently examined to acquire the needed information to determine if significant differences can be found between different GAC samples loaded with different adsorbed ion/molecules. Figure 4 depicts digital radiographies (using XRA) of GAC loaded with the highest adsorbate mass of nickel $\left(q_{e}=15.73 \mathrm{mg} / \mathrm{g}\right)$, cobalt $\left(q_{e}=49.95 \mathrm{mg} / \mathrm{g}\right), \mathrm{MB}$ $\left(q_{e}=259.3 \mathrm{mg} / \mathrm{g}\right)$ and iodine $\left(q_{e}=2638 \mathrm{mg} / \mathrm{g}\right)$ (see Section 2.3$)$ using 22, 27, 33, 40, 50, 60 and $70 \mathrm{keV}$ for nickel, cobalt and $\mathrm{MB}$ and 40,50, 60, 70, 80, 90 and $100 \mathrm{keV}$ for iodine.

An increase in energy causes a decrease in the grey-scale level obtained, due to a proportional increase of the penetration power of the incident photon beam. The obtained grey-scale level is proportional to the nature of the adsorbed molecule or ion and the number of pixels in that particular grey-level (spatial concentration, $S_{C}$ ) and is also related with its adsorbed amount $[15,16]$, keeping the sample thickness constant between experiments [15]. Higher $q_{e}$ values cause a higher amount of wither pixels (pixels at " 1 ") at the same irradiation energy, however a decreasing trend in the grey-scale values is observed with increasing energy of the incident beam. According to Figure 4, it is not possible to observe changes in the grey-scale radiographic images for nickel using energies values above $60 \mathrm{keV}$ (see $S_{C}$ values in Table 7) for $q_{e}=15.73 \mathrm{mg} / \mathrm{g}$. Cobalt shows a similar behavior, with no variations in the normalized grey-scale above $60 \mathrm{keV}$, with $q_{e}=43.95 \mathrm{mg} / \mathrm{g}$. Nickel and cobalt present almost equal atomic numbers $(Z=28$ and $Z=27$, respectively); thus, the grey-scale changes seen in radiographic images are mainly caused by adsorbed mass differences between the ions. MB also depicts a similar pattern (but not equal) with respect to nickel and cobalt when radiographic images are compared; the calculated $Z_{\text {eff }}$ for $\mathrm{MB}$ is the lowest of all analyzed ion/molecules $\left(Z_{e f f(M B)}=9\right)$. However, its $q_{e}$ value is 16 times higher in comparison with nickel and six times higher when compared with cobalt. There are no detectable changes in the grey-scale $\left(q_{e}=259.3 \mathrm{mg} / \mathrm{g}\right)$ when energies above $60 \mathrm{keV}$ are used. Its effective atomic number proves that $Z$ or $Z_{\text {eff }}$ cannot be used as a single fundamental parameter to describe differences. However, the adsorbed mass 
used for this ion is significantly higher than the adsorbate mass of nickel and cobalt onto GAC. No significant differences between iodine samples are found using energies values under $40 \mathrm{keV}$. At the same time, it is not possible to obtain a completely darker image for analyzed iodine samples. Considering the high atomic number and very high adsorbed mass values used for the adsorption study of iodine, it will take energy values above $150 \mathrm{keV}$ to achieve zero attenuation and obtain a completely dark image. X-ray equipment for medical diagnosis actually installed in hospitals cannot be used, since the maximum energy is usually $120 \mathrm{keV}$. In Figure 4, high grey-scale values can be observed for iodine using high-energy values up to $100 \mathrm{keV}$. Spatial concentration $\left(S_{C}\right)$ [15] of pixels at " 1 " in the normalized grey-scale was correlated with $q_{e}$ for each molecule or ion, at each used energy. Table 7 depicts $q_{e}$ and $S_{C}$ values for each used energy.

(a) Nickel

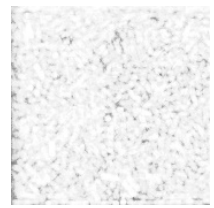

$22 \mathrm{keV}$

(b) Cobalt

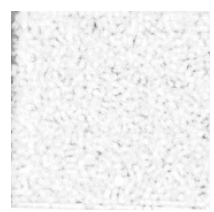

$22 \mathrm{keV}$

(c) $\mathrm{MB}$

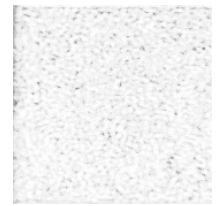

$22 \mathrm{keV}$

(d) Iodine

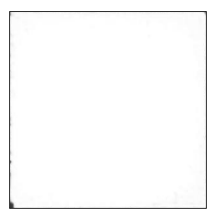

$40 \mathrm{keV}$

$$
\left(q_{e}=15.73 \mathrm{mg} / \mathrm{g}\right)
$$
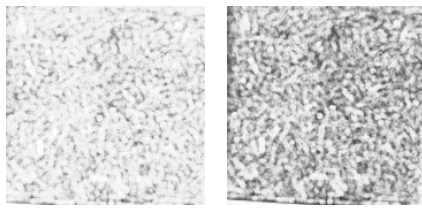

$27 \mathrm{keV}$

$33 \mathrm{keV}$

$\left(q_{e}=43.95 \mathrm{mg} / \mathrm{g}\right)$
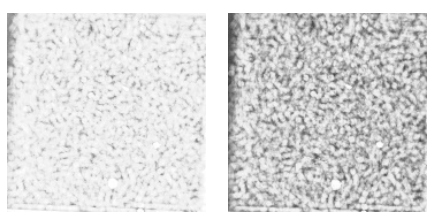

$27 \mathrm{keV}$

$33 \mathrm{keV}$

$\left(q_{e}=259.3 \mathrm{mg} / \mathrm{g}\right)$
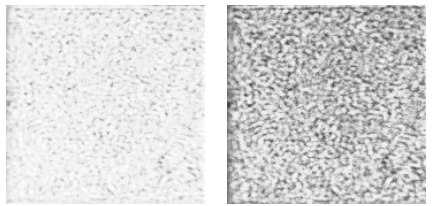

$27 \mathrm{keV}$

$33 \mathrm{keV}$
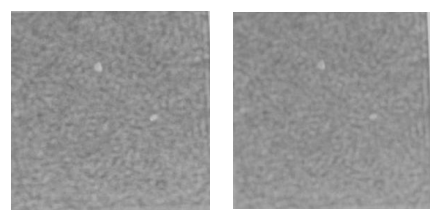

$40 \mathrm{keV}$

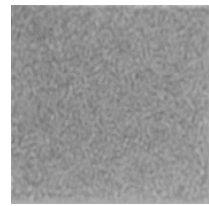

$40 \mathrm{keV}$

$\left(q_{e}=2638 \mathrm{mg} / \mathrm{g}\right)$

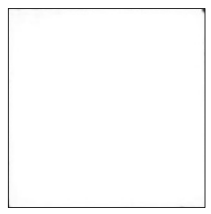

$50 \mathrm{keV}$

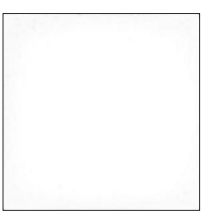

$60 \mathrm{keV}$

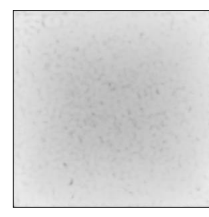

$70 \mathrm{keV}$

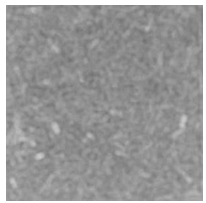

$50 \mathrm{keV}$

$50 \mathrm{keV}$

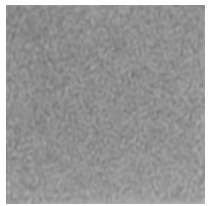

$50 \mathrm{keV}$

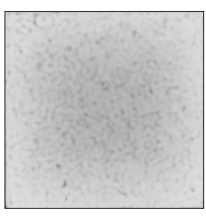

$80 \mathrm{keV}$

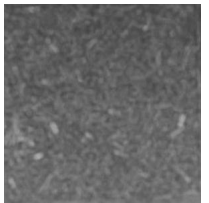

$60 \mathrm{keV}$

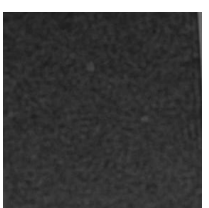

$60 \mathrm{keV}$

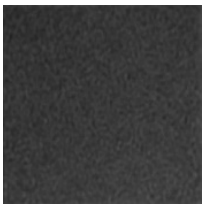

$60 \mathrm{keV}$

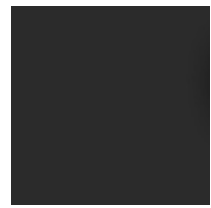

$70 \mathrm{keV}$

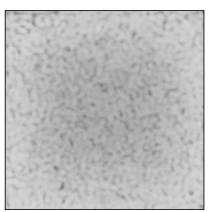

$90 \mathrm{keV}$

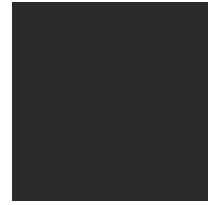

$70 \mathrm{keV}$

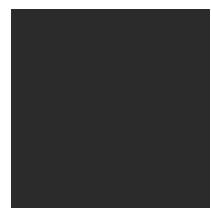

$70 \mathrm{keV}$

Figure 4. Digital radiographies taken at different energies for each adsorbed molecule/element onto GAC using different $q_{e}$ values: (a) for nickel; (b) for cobalt; (c) for MB and (d) for iodine. 
Table 7. $q_{e}$ and $S_{C}$ parameters found at different energies.

\begin{tabular}{|c|c|c|c|c|c|c|c|}
\hline Nickel & & & Pixels in & "1" & & & \\
\hline & $\begin{array}{c}q_{e} \\
(\mathrm{mg} / \mathrm{g})\end{array}$ & $\begin{array}{c}S_{C} \\
(22 \mathrm{keV})\end{array}$ & $\begin{array}{c}S_{C} \\
(27 \mathrm{keV})\end{array}$ & $\begin{array}{c}S_{C} \\
(33 \mathrm{keV})\end{array}$ & $\begin{array}{c}S_{C} \\
(40 \mathrm{keV})\end{array}$ & $\begin{array}{c}S_{C} \\
(50 \mathrm{keV})\end{array}$ & $\begin{array}{c}S_{C} \\
(60 \mathrm{keV})\end{array}$ \\
\hline & 0 & 0 & 0 & 0 & 0 & 0 & 0 \\
\hline & 1.46 & 3205 & 2 & 1 & 0 & 0 & 0 \\
\hline & 2.92 & 6410 & 4 & 2 & 0 & 0 & 0 \\
\hline & 5.09 & 12,365 & 371 & $\overline{4}$ & 0 & 0 & 0 \\
\hline & 7.27 & 18,320 & 738 & 6 & 0 & 0 & 0 \\
\hline & 11.51 & 19,186 & 1040 & 11 & 0 & 0 & 0 \\
\hline & 15.73 & 20,052 & 1342 & 17 & 0 & 0 & 0 \\
\hline \multirow[t]{9}{*}{ Cobalt } & & & Pixels in & "1" & & & \\
\hline & $\begin{array}{c}q_{e} \\
(\mathrm{mg} / \mathrm{g})\end{array}$ & $\begin{array}{c}S_{C} \\
(22 \mathrm{keV})\end{array}$ & $\begin{array}{c}S_{C} \\
(27 \mathrm{keV})\end{array}$ & $\begin{array}{c}S_{C} \\
(33 \mathrm{keV})\end{array}$ & $\begin{array}{c}S_{C} \\
(40 \mathrm{keV})\end{array}$ & $\begin{array}{c}S_{C} \\
(50 \mathrm{keV})\end{array}$ & $\begin{array}{c}S_{C} \\
(60 \mathrm{keV})\end{array}$ \\
\hline & 0 & 0 & 0 & 0 & 0 & 0 & 0 \\
\hline & 2.01 & 418 & 25 & 2 & 0 & 0 & 0 \\
\hline & 4.03 & 835 & 50 & 5 & 0 & 0 & 0 \\
\hline & 7.62 & 7192 & 222 & 97 & 0 & 0 & 0 \\
\hline & 11.21 & 13,550 & 395 & 190 & 0 & 0 & 0 \\
\hline & 27.58 & 13,800 & 621 & 227 & 0 & 0 & 0 \\
\hline & 43.95 & 14,050 & 848 & 265 & 0 & 0 & 0 \\
\hline \multirow[t]{9}{*}{ MB } & & & Pixels in & "1" & & & \\
\hline & $\begin{array}{c}q_{e} \\
(\mathrm{mg} / \mathrm{g})\end{array}$ & $\begin{array}{c}S_{C} \\
(22 \mathrm{keV})\end{array}$ & $\begin{array}{c}S_{C} \\
(27 \mathrm{keV})\end{array}$ & $\begin{array}{c}S_{C} \\
(33 \mathrm{keV})\end{array}$ & $\begin{array}{c}S_{C} \\
(40 \mathrm{keV})\end{array}$ & $\begin{array}{c}S_{C} \\
(50 \mathrm{keV})\end{array}$ & $\begin{array}{c}S_{C} \\
(60 \mathrm{keV})\end{array}$ \\
\hline & 0 & 0 & 0 & 0 & 0 & 0 & 0 \\
\hline & 49.97 & 3857 & 15 & 0 & 0 & 0 & 0 \\
\hline & 99.94 & 7714 & 30 & 0 & 0 & 0 & 0 \\
\hline & 145.31 & 11,607 & 51 & 0 & 0 & 0 & 0 \\
\hline & 190.68 & 15,500 & 73 & 0 & 0 & 0 & 0 \\
\hline & 224.99 & 21,315 & 637 & 0 & 0 & 0 & 0 \\
\hline & 259.3 & 27,130 & 1201 & 15 & 0 & 0 & 0 \\
\hline \multirow[t]{9}{*}{ Iodine } & & & Pixels in & “1" & & & \\
\hline & $\begin{array}{c}q_{e} \\
(\mathrm{mg} / \mathrm{g})\end{array}$ & $\begin{array}{c}S_{C} \\
(40 \mathrm{keV})\end{array}$ & $\begin{array}{c}S_{C} \\
(50 \mathrm{keV})\end{array}$ & $\begin{array}{c}S_{C} \\
(60 \mathrm{keV})\end{array}$ & $\begin{array}{c}S_{C} \\
(70 \mathrm{keV})\end{array}$ & $\begin{array}{c}S_{C} \\
(80 \mathrm{keV})\end{array}$ & $\begin{array}{c}S_{C} \\
(90 \mathrm{keV})\end{array}$ \\
\hline & 0 & 0 & 0 & 0 & 0 & 0 & 0 \\
\hline & 451 & 31,545 & 34,810 & 13,525 & 0 & 0 & 0 \\
\hline & 903 & 63,090 & 69,620 & 27,050 & 0 & 0 & 0 \\
\hline & 1232 & 51,470 & 74,755 & 36,060 & 0 & 0 & 0 \\
\hline & 1561 & 69,850 & 79,890 & 45,070 & 0 & 0 & 0 \\
\hline & 2099 & 57,575 & 81,285 & 51,985 & 0 & 0 & 0 \\
\hline & 2638 & 75,300 & 82,680 & 58,900 & 0 & 0 & 0 \\
\hline
\end{tabular}

For energy values between 22 and $33 \mathrm{keV}$, an initial intensity of $125 \mathrm{mAs}$ was used. For energies above $40 \mathrm{keV}$ an intensity of $40 \mathrm{mAs}$ was used for all experiments [15]. In Table 7, for energy values above $33 \mathrm{keV}$, no pixels in " 1 " can be noticed for nickel and cobalt. For MB, a similar trend for energies above $27 \mathrm{keV}$ can be observed. The same phenomena can be seen for iodine for energy values above $60 \mathrm{keV}$. The spatial concentration $\left(S_{C}\right)$ is correlated with $q_{e}$ values in order to find the energy value where the best correlation between $S_{C}$ and $q_{e}$ can be found for each adsorbed molecule or ion. Figure 5 depicts the correlation graphs between $S_{C}(\mathrm{XRA})$ and $q_{e}$ values of different adsorbed ions/molecule onto GAC at different energies. 


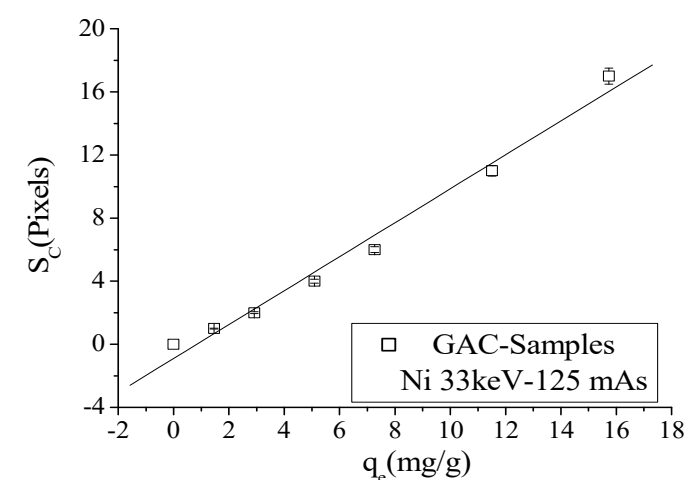

(a)

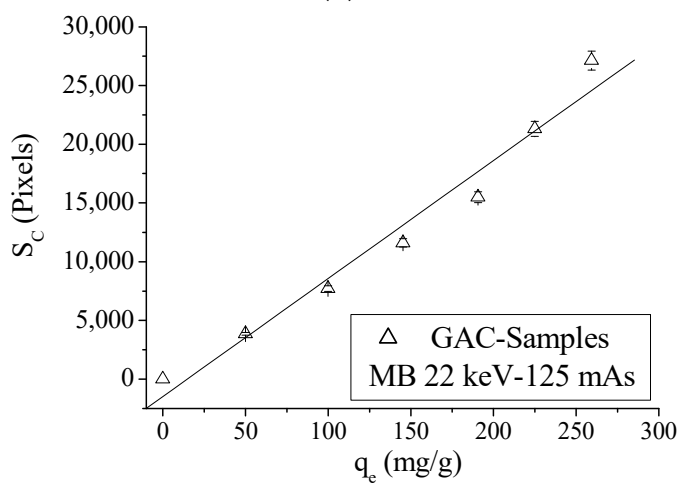

(c)

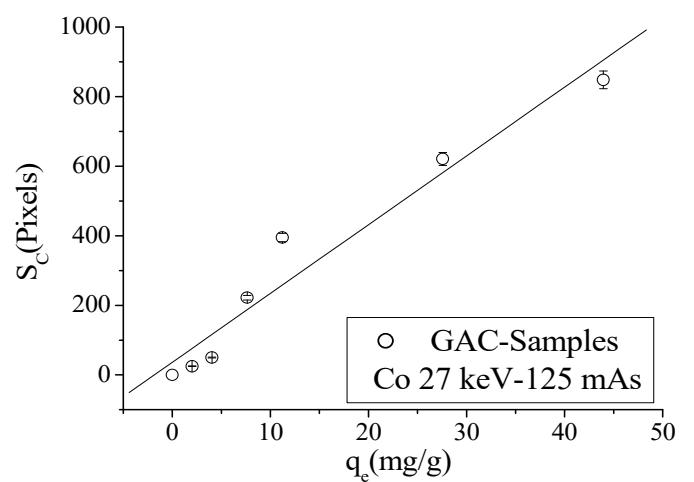

(b)

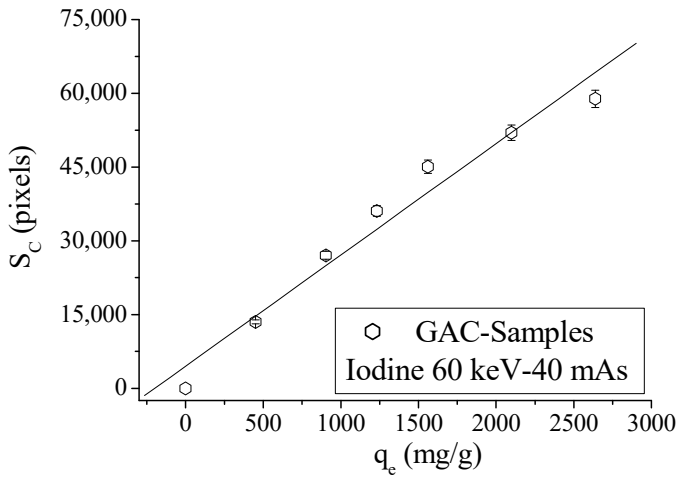

(d)

Figure 5. Correlation graphs between $S_{C}$ and $q_{e}$ values: (a) nickel; (b) cobalt; (c) MB; and (d) Iodine for virgin GAC and ion or molecule loaded GAC samples.

Correlation graphs between $S_{C}$ and $q_{e}$ values of analyzed ions or molecules evaluating other used energies are shown in Figure S1. Correlation parameters are presented in Table 8.

According to Table 8, good correlation coefficients can be found between $S_{C}$ and $q_{e}$ when an optimal energy for incident photons is used. For nickel, a fitting goodness of 0.99 is found at $33 \mathrm{keV}$ and 0.98 at $27 \mathrm{keV}$, both at $125 \mathrm{mAs}$. According to Equation (25), the optimal energy for this ion (for $q_{e}$ variations between 1.46 and $15.73 \mathrm{mg} / \mathrm{g}$ ) should be between 20 and $40 \mathrm{keV}$. For $c=$ cobalt, the best fitting result of 0.97 using $27 \mathrm{keV}$ is noticed. According to Equation (25) and calculating the estimated adsorbed mass of cobalt from $q_{e}$, the optimal energy values to describe the adsorption of cobalt onto GAC should be approximately between 26 and $51 \mathrm{keV}$ ( $q_{e}$ within the range of $2.01-43.95 \mathrm{mg} / \mathrm{g}$ ). MB shows the best correlation parameters only at $22 \mathrm{keV}$ and $125 \mathrm{mAs}$, with a 0.98 of fitting goodness. For this ion, optimal energy to describe its adsorption onto GAC should be between 16 and $24 \mathrm{keV}$ for found $q_{e}$ values (between 49.97 and $259.3 \mathrm{mg} / \mathrm{g}$ ) using Equation (25). Iodine is the adsorbed molecule with the highest atomic number $(Z=53)$, and it is also the compound with highest values of $q_{e}$. For this molecule, the best correlation parameter between $S_{C}$ and $q_{e}$ is only found for $60 \mathrm{keV}$ and $40 \mathrm{mAs}$ with a 0.98 fitting goodness. Predicted energy values for $q_{e}$ values between 451.5 and $2638 \mathrm{mg} / \mathrm{g}$ are approximately between 50 and $74 \mathrm{keV}$ using Equation (25).

Digital image histograms obtained after the application of XRA technique to each analyzed sample were calculated using MATLAB ${ }^{\circledR} 2015$. A combination process of those histograms was applied to obtain an absorption signature for each adsorbed molecule or ion in the studied energy range. A combination of histograms is shown in Figure 6 using nickel as an example at different $q_{e}$ values keeping the energy constant (Figure 6a) and changing the energy range between 22 and $70 \mathrm{keV}$ while keeping $q_{e}$ constant (Figure 6b). 
Table 8. Fitting parameters found for $q_{e}$ value versus $S c$ parameter (XRA) for each adsorbed molecule or ion.

\begin{tabular}{|c|c|c|c|c|c|}
\hline \multicolumn{6}{|c|}{ Nickel } \\
\hline Evaluated Parameter & $A$ (Pixels) & $e(A)$ & $\begin{array}{c}B \\
\text { (Pixels.g/mg) }\end{array}$ & $e(B)$ & $R^{2}$ \\
\hline $\mathrm{S}_{\mathrm{C}}(22 \mathrm{keV}-125 \mathrm{mAs})$ & 3027 & \pm 4 & 1326 & \pm 162 & 0.91 \\
\hline $\mathrm{S}_{\mathrm{C}}(27 \mathrm{keV}-125 \mathrm{mAs})$ & -98 & \pm 7 & 95 & \pm 8 & 0.98 \\
\hline $\mathrm{S}_{\mathrm{C}}(33 \mathrm{keV}-125 \mathrm{mAs})$ & -0.900 & \pm 0.001 & 1.03 & \pm 0.05 & 0.99 \\
\hline \multicolumn{6}{|c|}{ Cobalt } \\
\hline Evaluated Parameter & $A$ (Pixels) & $e(A)$ & $\begin{array}{c}B \\
\text { (Pixels.g/mg) }\end{array}$ & $e(B)$ & $R^{2}$ \\
\hline $\mathrm{S}_{\mathrm{C}}(22 \mathrm{keV}-125 \mathrm{mAs})$ & 2533 & \pm 200 & 333 & \pm 10 & 0.81 \\
\hline $\mathrm{S}_{\mathrm{C}}(27 \mathrm{keV}-125 \mathrm{mAs})$ & 36 & \pm 10 & 20 & \pm 2 & 0.97 \\
\hline $\mathrm{S}_{\mathrm{C}}(33 \mathrm{keV}-125 \mathrm{mAs})$ & 25 & \pm 12 & 6 & \pm 1 & 0.89 \\
\hline \multicolumn{6}{|c|}{ Methylene Blue } \\
\hline Evaluated Parameter & $A$ (Pixels) & $e(A)$ & $\begin{array}{c}B \\
\text { (Pixels.g/mg) }\end{array}$ & $e(B)$ & $R^{2}$ \\
\hline $\mathrm{S}_{\mathrm{C}}(22 \mathrm{keV}-125 \mathrm{mAs})$ & -1481 & \pm 129 & 100 & \pm 8 & 0.98 \\
\hline $\mathrm{S}_{\mathrm{C}}(27 \mathrm{keV}-125 \mathrm{mAs})$ & -237 & \pm 23 & 4 & \pm 1 & 0.76 \\
\hline $\mathrm{S}_{\mathrm{C}}(33 \mathrm{keV}-125 \mathrm{mAs})$ & -2.56 & \pm 0.54 & 0.03 & \pm 0.02 & 0.56 \\
\hline \multicolumn{6}{|c|}{ Iodine } \\
\hline Evaluated Parameter & $A$ (Pixels) & $e(A)$ & $\begin{array}{c}B \\
\text { (Pixels.g/mg) }\end{array}$ & $e(B)$ & $R^{2}$ \\
\hline $\mathrm{S}_{\mathrm{C}}(40 \mathrm{keV}-40 \mathrm{mAs})$ & 19,647 & \pm 160 & 24 & \pm 7 & 0.83 \\
\hline $\mathrm{S}_{\mathrm{C}}(50 \mathrm{keV}-40 \mathrm{mAs})$ & 23,536 & \pm 122 & 29 & \pm 8 & 0.85 \\
\hline $\mathrm{S}_{\mathrm{C}}(60 \mathrm{keV}-40 \mathrm{mAs})$ & 4498 & \pm 50 & 22 & \pm 2 & 0.98 \\
\hline
\end{tabular}

$S_{C}=A+B . q_{e}($ with $e(i)$ the error on parameter $i)$.

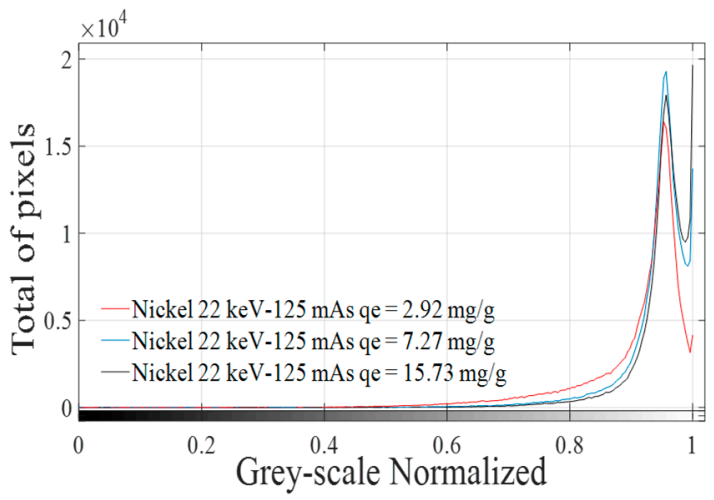

(a)

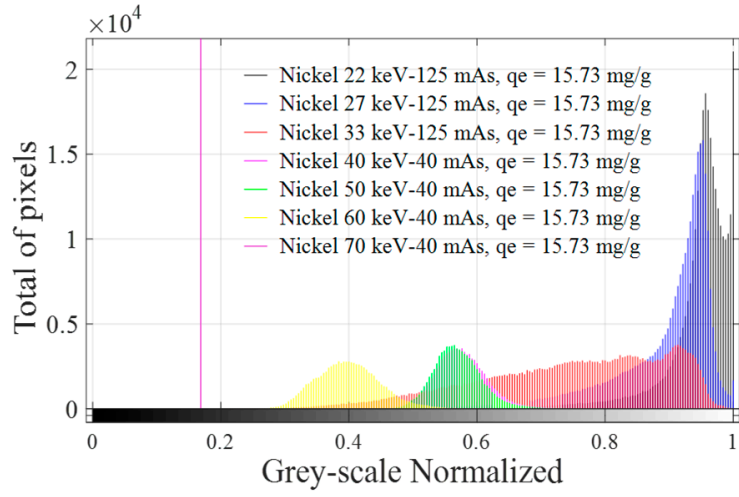

(b)

Figure 6. Combination of image histograms of nickel radiographies at: different $q_{e}$ values and constant energy (22 keV) (a); and different energies at the same $q_{e}$ value $(15.73 \mathrm{mg} / \mathrm{g})(\mathbf{b})$.

According to Figure 6a, the same pattern is found for different values of adsorbed mass using $q_{e}$ values, despite significant changes in the spatial concentration of pixels in " 1 ", as can be seen in Table 7 . Significant differences for pixels at " 1 " are more difficult to detect when $q_{e}$ increases, making the judgment of resolution difficult. Increasing the penetration power could be a solution for bandwidth problems, which is narrower with increasing $q_{e}$ values. Doing this and considering that the same pattern is obtained when different adsorbed masses are evaluated, for a fixed selected $q_{e}$ value (e.g., $q_{e}=15.73 \mathrm{mg} / \mathrm{g}$ ), image histograms obtained at each irradiation energy are combined in one plot, as shown 
in Figure 6b. The method previously explained was applied for all explored ions and molecule identifying characteristics peaks for each adsorbed ion or molecule in the energy range used. Considering that changes in $q_{e}$ only cause changes in the spatial concentration and not in the grey-scale level, maximum $q_{e}$ values for each adsorbed molecule or ion were selected and the combination process, as displayed in Figure 6b, was applied for all GAC samples, as shown in Figure 7, at each irradiation energy.

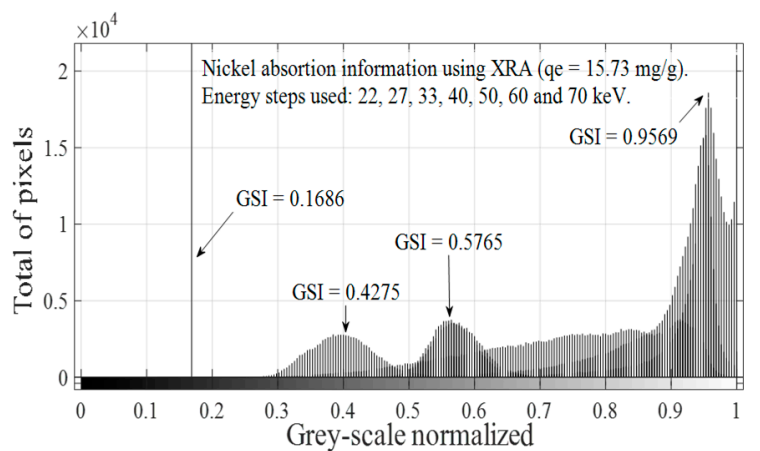

(a)

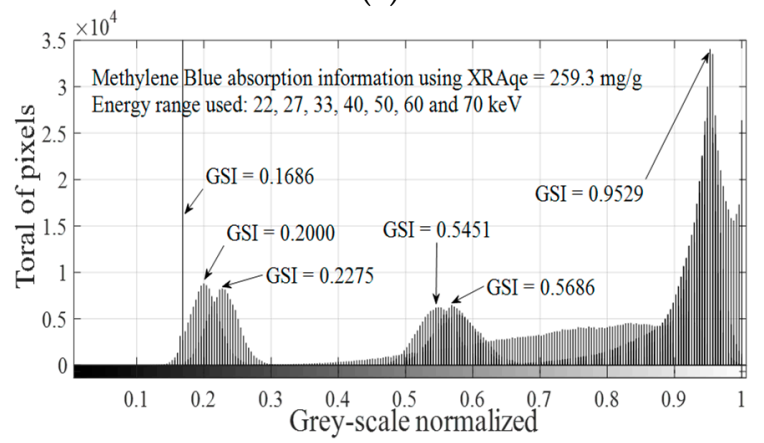

(c)

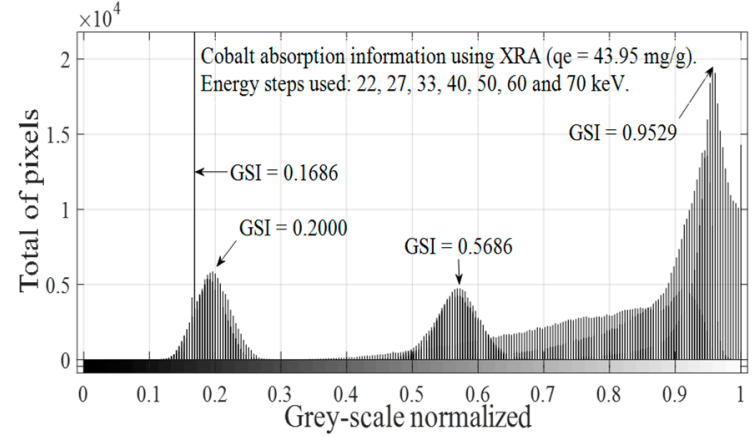

(b)

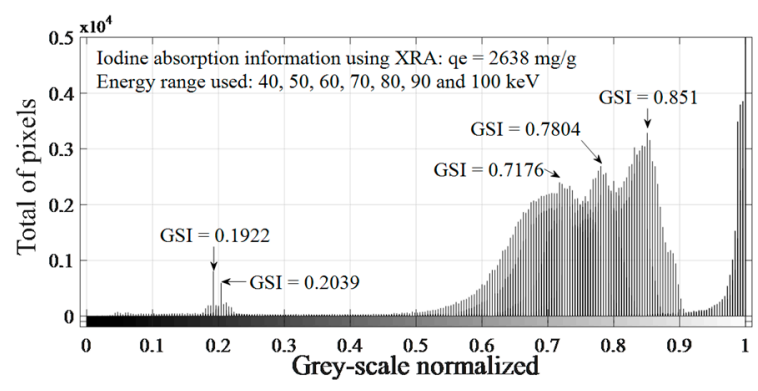

(d)

Figure 7. Histogram combined strategy using XRA data for: nickel (a); cobalt (b); MB (c); and Iodine (d).

In Figure 7, it is possible to observe different patterns for each analyzed molecule or ion. Nickel presents distinctive peaks at $G S I=0.1686, G S I=0.4275, G S I=0.5765$ and $G S I=0.9569$. Cobalt shows typical peaks at $G S I=0.1686, G S I=0.2000, G S I=0.5686$ and $G S I=0.9529$. MB shows typical peaks at $G S I=0.1686, G S I=0.2000, G S I=0.2275$, $G S I=0.5451, G S I=0.5686$ and $G S I=0.9529$. For MB, four GSI values matched with GSI values of cobalt $(G S I=0.1686, G S I=0.2000, G S I=0.5686$ and $G S I=0.9529)$, but with different total pixel values, and only one matched with nickel $(G S I=0.1686)$. The GSI peak at 0.1686 is a very narrow peak with a very high maximum total pixel value of 115,000 . Iodine depicts an absorption signature slightly different in comparison with nickel, cobalt and MB. In this case, higher GSI values are found for each irradiation energy, which is consistent with iodine high atomic number and larger $q_{e}$ values found for its adsorption onto GAC1. For this molecule, characteristic peaks are found at $G S I=0.1922, G S I=0.2039$, $G S I=0.7176, G S I=0.7804$ and $G S I=0.8510$. Figure 7 shows different patterns for different adsorbed molecule or ions onto GAC1 by the XRA method. Typical GSI values were found for each analyzed ion or molecule in the used energy range, which can be used as a digital signature for each adsorbed molecule or ion using the histograms combination strategy. For instance, if more than four peaks are found in the histogram combination figure of GSI for $\mathrm{MB}$ and $\mathrm{Co}$, GSI peaks at 0.2275 and at 0.5451 can be used to prove the presence of MB in a solution instead of $\mathrm{Co}$. For $\mathrm{Ni}$ and $I_{2}$, differentiation is easier since the pattern of their combined GSI peaks is unique and characteristic. 


\subsection{Probability Approach}

To verify the reliability of the application of obtained model (Equation (25)) to describe the photon absorption of adsorbed molecule or ion onto GAC, a probability model (Equation (29)) was developed to verify if experimental values are in concordance with the literature. However, Equation (25) is a proportional equation expressed in terms of $\mathrm{keV}$. Therefore, testing this model and its ability to describe the experimental data obtained are required. To develop this test, a comparison between experimental data and proposed model is done using Equation (29). The ratio of energy values $\left(E_{1}\right.$ and $\left.E_{2}\right)$ for a pair of ions or molecules or an ion and molecule obtained experimentally using XRA experiments (left half of Equation (29)) is compared to the ratio of corresponding energy values obtained using Equation (25) (right half of Equation (29)). If the obtained model is accurate to describe obtained data, the error between the ratio of energy values obtained experimentally and by calculation should be small. Equation (29) gives the possibility to evaluate the relationship between the ratio of energy values of two ions or molecules or between an ion and molecule and its effective dependency of photoelectric effective section. This evaluation allows obtaining 3D graphs for studying changes in the effective dependency of photoelectric effective section in order to see if obtained values are within the range reported in the literature [11-14]. Figure 8 depicts 3D plots of developed model.

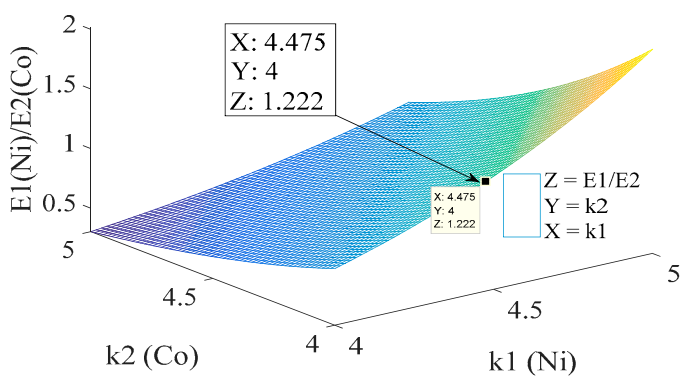

(a)

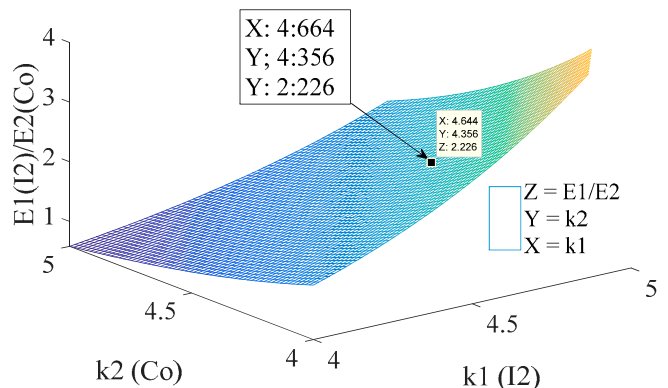

(c)

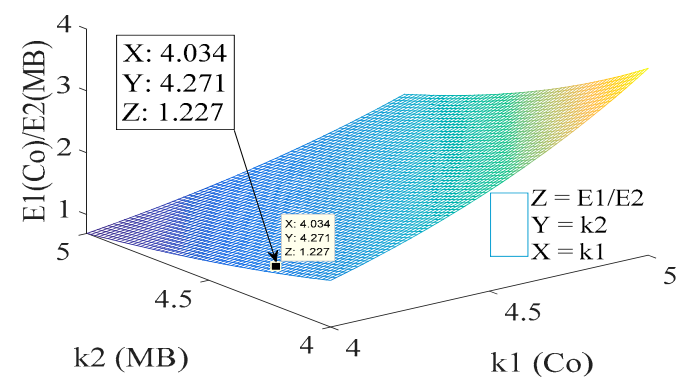

(e)

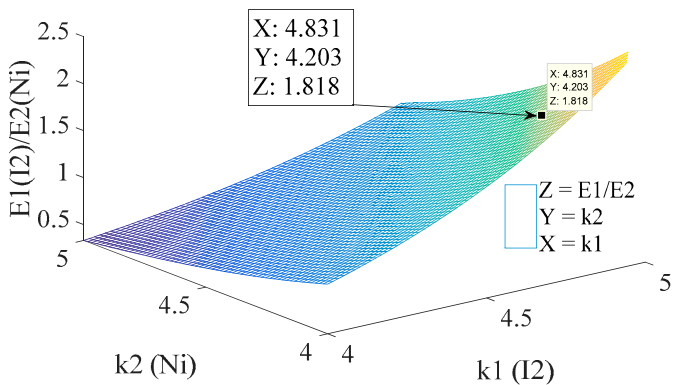

(b)

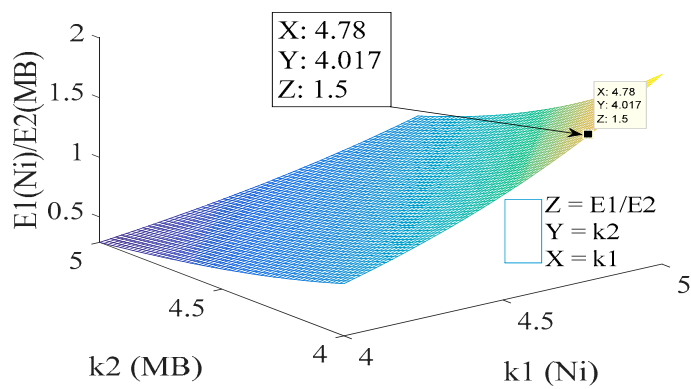

(d)

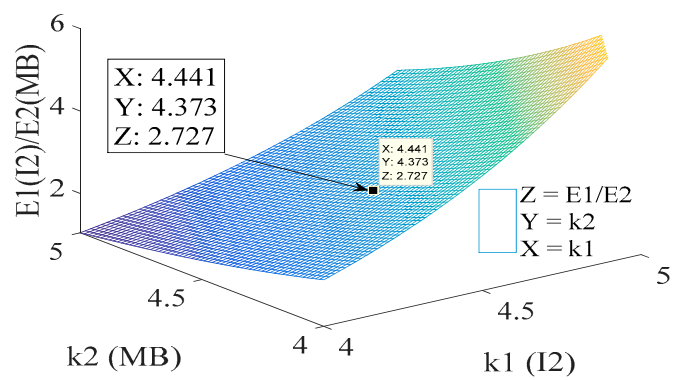

(f)

Figure 8. 3D plots for comparison: nickel vs. cobalt (a); iodine vs. nickel (b); iodine vs. cobalt (c); nickel vs. MB (d); cobalt vs. MB (e); and iodine vs. MB (f). 
Figure 8 shows 3D plots where the relationship between the ratio of obtained energies (energy with best correlation parameters between $S_{C}$ and $q_{e}$ ) for each adsorbed ion or molecule is shown on the z-axis. The $\mathrm{x}$ - and $\mathrm{y}$-axes represent the effective dependency of photoelectric effective section $(k)$ with effective atomic or atomic number for each adsorbed molecule or ion. In this probability comparison, the effective dependency of photoelectric effective section with energy ( $l$ ) remains constant (3.5) and $k$ is between 4 and 5, except for MB, where $k=4$ and $l=3$ (see Equation (29)), mainly caused by the low effective atomic number of MB. According to the literature, ions or molecules with low atomic number (or effective atomic number) should be analyzed using the lowest values of $k$ and $l[11,12]$. For a comparison between ions/elements, the ratio of obtained energies where the best correlation is found between $S_{C}$ and $q_{e}$ is used. For nickel and cobalt (Figure 8a), a value of approximately 1.222 is found while the experimental result is around 1.222 $(=33 \mathrm{keV} / 27 \mathrm{keV})$. Obtained error is approximately 0.0002 (around $0.02 \%)$. Values of $k$ for both elements are within reported range in the literature being between 4 and 5:4.5 for nickel $\left(k_{1}\right)$ and 4 for cobalt $\left(k_{2}\right)$ approximately. Considering that the differences between nickel and cobalt are mostly caused by differences in adsorbed mass, similar values for the effective dependency of photoelectric effective section are expected because of comparable atomic numbers. In Figure $8 b$, a comparison between iodine and nickel is presented. According to experimental data, the relationship between the ratio of energies $(60 \mathrm{keV} / 33 \mathrm{keV})$ is 1.8181 . Using the probability approach, a value of $1.818\left(E_{\mathrm{I} 2} / E_{\mathrm{Ni}}\right)$ is obtained, representing an error of $0.01 \%$ with respect to experimental results. The effective dependency of photoelectric effective section with atomic number is within a reported range from $4.8\left(k_{\mathrm{Ni}}\right)$ to $4.2\left(k_{\mathrm{I} 2}\right)$ for iodine and nickel, respectively. The same procedure was used comparing iodine vs. cobalt, nickel vs. MB, cobalt vs. $\mathrm{MB}$ and iodine vs. MB. In the first case (Figure $8 \mathrm{c}$ ), an error of $0.4 \%$ with respect to experimental data is found when energies values are compared, with values for $k$ within the reported range (approximately 4.6 for $I_{2}$ and 4.3 for Co) [11-14]. When MB and nickel (Figure $8 \mathrm{~d}$ ) are compared, $k$ and $l$ should be modified for MB, considering its low effective atomic number. After modification, a deviation from experimental values of $0.2 \%$ is obtained when obtained energies are compared while $k$ values ( 4.8 for MB and 4.1 for $\mathrm{Ni}$ ) are within the expected range. The same procedure was applied for the comparison cobalt vs. $\mathrm{MB}$ and iodine vs. $\mathrm{MB}$, obtaining errors of $0.2 \%$, respectively, for $k$ values around 4 and 4.3 (Co vs. MB) and 4.4 and 4.3 ( $I_{2}$ vs. $\left.\mathrm{MB}\right)$.

\section{Conclusions}

The adsorption process of nickel, cobalt, Methylene Blue and iodine onto GAC was best described by the Freundlich isotherm.

A proportional dependency was found between incident energy to achieve maximum photon attenuation and adsorbed mass, effective atomic number or atomic number and molar or atomic mass on GAC loaded with nickel, cobalt, MB and iodine.

XRA results were used in combination with image histograms to obtain a digital signature of adsorbed ions or molecules onto GAC. Distinct GSI values were found for each adsorbed molecule or ion within the used energy range. It was proved that differentiation can be made between adsorbed ions or molecules using this technique.

Experimental results were compared with probability models, indicating that experimental data obtained are within reported values in the literature [11].

Finally, it was demonstrated that XRA has potential for monitoring (multi-)ion and/or molecule(s) combinations on GACs using advanced digital image processing techniques.

Supplementary Materials: The following are available online at https:/ / www.mdpi.com/1996-194 4/14/1/91/s1, Figure S1: Correlation graphs between $S_{C}$ and $q_{e}$ values (a) nickel, (b) cobalt, (c) MB and (d) Iodine for virgin GAC1 and ion or molecule loaded GAC1 samples.

Author Contributions: Conceptualization, J.P.T. and H.C.S.; methodology, J.P.T., H.C.S., J.Y. and R.C.; software, J.P.T.; validation, J.P.T., T.M.P. and H.C.S.; formal analysis., J.P.T., H.C.S., J.Y., R.C. and P.A.; investigation, J.P.T., H.C.S. and T.M.P.; resources, J.Y., Á.B.S. and P.A.; data curation, J.P.T. and H.C.S.; 
writing-original draft preparation, J.P.T. and H.C.S.; writing—review and editing, J.P.T., H.C.S., J.Y., R.C. and Á.B.S.; visualization, J.P.T. and H.C.S.; supervision, J.Y., H.C.S., Á.B.S., R.C. and P.A.; project administration, H.C.S. and J.Y. All authors have read and agreed to the published version of the manuscript.

Funding: This research received no external funding.

Institutional Review Board Statement: Not applicable.

Informed Consent Statement: Not applicable.

Data Availability Statement: Data sharing is not applicable to this article because of authorized issues.

Acknowledgments: The authors thank VLIR-UOS (Flemish Interuniversity Council for University Development Cooperation) project between Belgium and Cuba for the support of the current and future studies. The raw/processed data required to reproduce these findings cannot be shared at this time as the data also form part of an ongoing study.

Conflicts of Interest: The authors declare no conflict of interest.

\section{References}

1. Van Grieken, R.; Markowicz, A. Handbook of X-ray Spectrometry; CRC Press: Boca Raton, FL, USA, 2001.

2. Depristo, A.E.; Augustin, S.D.; Ramaswamy, R.; Rabitz, H. Quantum number and energy scaling for nonreactive collisions. J. Chem. Phys. 1979, 71, 850-865. [CrossRef]

3. Massimi, M. Pauli's Exclusion Principle: The Origin and Validation of a Scientific Principle; Cambridge University Press: Cambridge, UK, 2005.

4. Gonzalez, R.C.; Woods, R.E.; Eddins, S.L. Digital Image Processing Using MATLAB; Person: London, UK, 2004.

5. Vanderheyden, S.R.H.; Yperman, J.; Carleer, R.; Schreurs, S. Enhanced cesium removal from real matrices by nickelhexacyanoferrate modified activated carbons. Chemosphere 2018, 202, 569-575. [CrossRef] [PubMed]

6. Vanreppelen, K.; Vanderheyden, S.; Schreurs, S.; Yperman, J.; Băbeanu, N.; Carleer, R. Activated carbon from pyrolysis of brewer's spent grain: Production and adsorption properties. Waste Manag. Res. 2014, 32, 634-645. [CrossRef] [PubMed]

7. Veith, J.; Sposito, G. On the use of the Langmuir equation in the interpretation of "adsorption" phenomena. Soil. Sci. Soc. Am. J. 1977, 41, 697-702. [CrossRef]

8. Harter, R.D.; Smith, G. Langmuir equation and alternate methods of studying "adsorption" reactions in soils. Chem. Soil Environ. 1981, 40, 167-182.

9. Tran, H.N.; You, S.-J.; Hosseini-Bandegharaei, A.; Chao, H.-P. Mistakes and inconsistencies regarding adsorption of contaminants from aqueous solutions: A critical review. Water Res. 2017, 120, 88-116. [CrossRef] [PubMed]

10. Reed, B.E.; Matsumoto, M. Modeling Cadmium Adsorption by Activated Carbon Using the Langmuir and Freundlich Isotherm Expressions. Sep. Sci. Technol. 1993, 28, 2179-2195. [CrossRef]

11. Johns, H.; Cunningham, J. The Physics of Radiology, 4th ed.; Charles C Thomas Publisher: Springfield, IL, USA, 1983.

12. Kumar, A. Studies on effective atomic numbers and electron densities of nucleobases in DNA. Radiat. Phys. Chem. 2016, 127, 48-55. [CrossRef]

13. Taylor, M.L.; Smith, R.L.; Dossing, F.; Franich, R.D. Robust calculation of effective atomic numbers: The Auto-Zeff software. Med. Phys. 2012, 39, 1769-1778. [CrossRef] [PubMed]

14. Tonguc, B.T.; Arslan, H.; Al-Buriahi, M. Studies on mass attenuation coefficients, effective atomic numbers and electron densities for some biomolecules. Radiat. Phys. Chem. 2018, 153, 86-91. [CrossRef]

15. Torres, J.P.; Sariol, H.C.; Yperman, J.; Sauvanell, Á.B.; Carleer, R.; Campa, J.N. A novel X-ray radiography approach for the characterization of granular activated carbons used in the rum production. J. Anal. Sci. Technol. 2018, 9, 1. [CrossRef]

16. Torres, J.P.; Sariol, H.C.; Yperman, J.; Adriaensens, P.; Carleer, R.; Peacok, T.M.; Sauvanell, Á.B.; Thijssen, E.; Reggers, G.; Haeldermans, T.; et al. X-ray absorption as an alternative method to determine the exhausting degree of activated carbon layers in water treatment system for medical services. Talanta 2019, 205, 120058. [CrossRef] [PubMed] 